$\xi=-1$

\title{
The effects of particle size distribution and sintering conditions on bending strength of sintered $\mathrm{Ni}-30 \% \mathrm{Fe}$ alloys
}

\author{
Mxolisi B. Shongwe ${ }^{1}$, Olawale O. Ajibola ${ }^{2 *}$, Munyadziwa M. Ramakokovhu ${ }^{1}$, Peter A. Olubambi ${ }^{2}$ \\ ${ }^{1}$ Institute for Nano-Engineering Research, Department of Chemical, Metallurgical and Materials Engineering, Tshwane University of \\ Technology, Pretoria, South Africa \\ ${ }^{2}$ Centre of NanoEngineering and Tribocorrosion, University of Johannesburg, Johannesburg, South Africa \\ *Corresponding author E-mail: olawalea@uj.ac.za
}

\begin{abstract}
This work reports effect of the powder grain size distributions on the bending strength sintered Ni-30\%Fe alloys obtained from mixed coarse-fine micron size metal powders. Two dissimilar particle sizes of $\mathrm{Ni}$ and Fe metal powders were mixed by subjecting them to translational and rotational agitations using the T2F Turbula Shaker Mixer. The mixed powders were moulded using graphite dies and sintered in vacuum and at constant pressure using Spark Plasma Sintering furnace (HHPD-25). The ratios of the two metals were varied as well as the sintering temperature and time. The morphology and microstructures of both powders and sinters were studied using field emission scanning electron microscopy (JSM-7600F) equipped with energy dispersive X-ray spectrometer (EDS) facilities. The phases in the sintered specimens were characterized by X-ray diffraction (XRD). The densities of the samples were determined, The Vickers microhardness at room temperature and bending strength of the sintered alloy specimens were measured. Comparatively, low heating rate $\left(50^{\circ} \mathrm{C} / \mathrm{min}\right)$ produced enhanced microstructures hence higher bonding, bending strength and densification than samples at high heating rate $\left(150^{\circ} \mathrm{C} / \mathrm{min}\right)$.
\end{abstract}

Keywords: Sintering; Grains; Bending Strength; Particle Size.

\section{Introduction}

The use of advanced materials in different areas of modern technology has lead to enhancement in the function, quality and performance of engineering parts and systems [1]. Nickel-base alloys are unique with combinations of properties making them useful in diverse dedicated applications. The soft magnetic properties of Ni$\mathrm{Fe}$ alloys are used in electronic, electromagnets and communication equipments. $\mathrm{Ni}-\mathrm{Fe}$ alloys have low expansion characteristics due to balance between thermal expansion and magnetic property changes with temperature. Also Ni-Fe alloys are useful in storage and transportation tanks for liquid natural gas industry; transducers (45-50Ni-Fe), magnetic amplifiers (oriented 49Ni-Fe), sensitive direct current relays $(45-49 \mathrm{Ni}-\mathrm{Fe}, 78.5 \mathrm{Ni}-\mathrm{Fe})$, temperature compensator (29-36 Ni-Fe), shielding (49Ni-Fe), dry reed magnetic switches DRMS (51Ni-Fe), chart recorder (instrument) and synchronous motors (49Ni-Fe).

Some other properties of significance that enlarge the usefulness of Ni alloys include: the shape memory characteristics of nickel alloys, the high strength at elevated temperatures, and the resistance to stress relaxation. Soft magnetic Ni-Fe alloys consisting about 30 to $80 \% \mathrm{Ni}$ are used extensively for their high saturation magnetostriction and constant permeability with changing temperature. For high expectation of ductility and malleability, Ni-Fe alloys are usually made as strip or sheet product; though, billet, bar, and wire can be produced as required [2]

Production of cast Ni-Fe from melt can be difficult due to the chemical reactivity of the melt that frequently results in segregation defects [3]. Powder metallurgy (PM) methods to formulate Ni-SMA were affected by the complications faced with usual methods. PM is a practice that lessens the problems related to liquid metal casting, permits a precise composition management and the capability to manufacture a range of components shapes.

Therefore, conventional sintering is seen as a viable method of making porous Ni SMA [4]. However, dense materials are not easy to attain, mostly when starting with elemental powder [5]. Sintering process can be realized in the two-stage regime; involving the preliminary sintering of $\mathrm{P} / \mathrm{M}$ compacts in solid phase and the final sintering with liquid phase executed in vacuum [6].

Sinter-hardening technique SHT presents another way of hardening metal powder components beside the traditional austenitization, quenching, and tempering routines. SHT has numerous advantages such as the reduced number of manufacturing procedures and averting part contamination with oil. SHT can be accomplished in different ways as using sintering furnaces with customized ferrous PM alloy admixture systems and using dedicated PM alloys in combination with furnaces having fast cooling zones. SHT compact the PM component, sinter, and temper in a cycle with optimization of each step to guarantee consistent making of sinter-hardened parts [7].

Though, there are reports on the binary alloys of Nickel with iron group elements. The gap still exists in relating and understanding the roles of diversities in powder metal grain sizes as regarding the densification and sintering parameters on the enhancing superior mechanical (bending strength) and magnetic characteristics (microstructure) of Ni-Fe alloy in particular [8-11]. There is still great necessity to investigate the Ni-Fe alloy systems more intensely. Hence this work studied the influence of grain particle size distribution and sintering parameters (Heating rate $\left({ }^{\circ} \mathrm{C} / \mathrm{min}\right)$, reference temperature $\left({ }^{\circ} \mathrm{C}\right)$ and dwell time $\left.(\mathrm{min})\right)$ on the bending strength of the sintered $\mathrm{Ni}-30 \% \mathrm{Fe}$ alloys produced from the mixture of 
coarse-fine micron sized powders. It reflects the aspect of the larger scope partly reported in the previous literatures [10-12].

\section{Experimental procedures}

\subsection{Material preparation}

Two different particle sizes of elemental $\mathrm{Ni}$ and $\mathrm{Fe}$ powders with composition summarized in Table 1 were selected as starting materials. A $250 \mathrm{ml}$ cylindrical plastic vessel with a powder fill level of $10 \%$ was loaded axially, placed in the mixing chamber and subjected to combined translational and rotational agitations. The coarse and fine sizes of $\mathrm{Ni}$ and Fe powders were dry mixed using the Turbula Shaking Mixer T2F at speed of $49 \mathrm{rpm}$ and time of $5 \mathrm{~h}$. The morphology of the as received and blended powders were then examined with a field emission scanning electron microscopy (FESEM, JSM-7600F, Jeol, Japan) equipped with energy dispersive X-ray spectrometer (EDS) facilities.

Table 1: Chemical Compositions of the Elemental Powders

\begin{tabular}{llllllll}
\hline Elemental & Purity & \multicolumn{3}{c}{ Particle Size $\mathrm{D}_{50}$} & \multicolumn{3}{c}{ Main impurity (wt. \%) } \\
\hline powder & $(\%)$ & $\mathrm{Fe}$ & $\mathrm{Ni}$ & Mixture & $\mathrm{C}$ & $\mathrm{O}$ & $\mathrm{P}$ \\
$\mathrm{Ni}-30 \% \mathrm{Fe}$ & 99.5 & 44 & 70 & $\leq 70$ & $\leq 0.002$ & $\leq 0.07$ & 0.0008 \\
$\mathrm{Ni}-30 \% \mathrm{Fe}$ & 99.5 & 3 & 0.3 & $\leq 3$ & $\leq 0.09$ & $\leq 0.08$ & 0.0003 \\
\hline
\end{tabular}

\subsection{Sintering procedure}

The mixed powders were packed in $30 \mathrm{~mm}$ inner-diameter graphite dies, lagged with $0.2 \mathrm{~mm}$ thick graphite foils; and sintered by SPS (HHPD-25, FCT GmbH Germany). The graphite foils afford easy removal of the sinter and significant reduction of temperature inhomogeneities. In addition, the die exterior was covered with $\sim 10 \mathrm{~mm}$ thick porous graphite felt, used as a thermal insulation to reduce the radiation loss and possible temperature gradient [8-9]. Sintering was done in vacuum and at constant pressure of $30 \mathrm{MPa}$ In all cases, heating schedules were controlled by a preset heating program as shown in Table 2. At the end of the heating regime (temperature and time); the electric current was shut off, the applied stress released, and the specimens were furnace cooled. The temperature was measured by an optical pyrometer implanted at 3 $\mathrm{mm}$ from the top of the sample surface in the SPS apparatus. Sinter discs of approximately $30 \mathrm{~mm}$ diameter by $5 \mathrm{~mm}$ high were produced.

Table 2: Sintering Schedules to Consolidate Blended Powders

\begin{tabular}{|c|c|c|c|}
\hline \multirow[b]{2}{*}{ Alloy(particle sizes) } & \multicolumn{3}{|c|}{ Sintering conditions } \\
\hline & $\begin{array}{l}\text { Heating-rate } \\
\left({ }^{\circ} \mathrm{C} / \mathrm{min}\right)\end{array}$ & $\begin{array}{l}\text { Reference- } \\
\text { temperature }\left({ }^{\circ} \mathrm{C}\right)\end{array}$ & $\begin{array}{l}\text { Dwell time } \\
\text { (min) }\end{array}$ \\
\hline $\begin{array}{l}\mathrm{Ni}-30 \% \mathrm{Fe}(70 \mu \mathrm{m} \\
\mathrm{Ni}, 44 \mu \mathrm{m} \mathrm{Fe})\end{array}$ & 50 & 1100 & 2 \\
\hline $\begin{array}{l}\mathrm{Ni}-30 \% \mathrm{Fe}(0.3 \mu \mathrm{m} \\
\mathrm{Ni}, 3 \mu \mathrm{m} \mathrm{Fe})\end{array}$ & 50 & 1100 & 2 \\
\hline $\begin{array}{l}\mathrm{Ni}-30 \% \mathrm{Fe}(70 \mu \mathrm{m} \\
\mathrm{Ni}, 44 \mu \mathrm{m} \mathrm{Fe})\end{array}$ & 150 & 1100 & 2 \\
\hline $\begin{array}{l}\mathrm{Ni}-30 \% \mathrm{Fe}(0.3 \mu \mathrm{m} \\
\mathrm{Ni}, 3 \mu \mathrm{m} \mathrm{Fe})\end{array}$ & 150 & 1100 & 2 \\
\hline
\end{tabular}

\subsection{Density and microstructural characterization}

The sintered specimens' surfaces were ground and polished to remove any graphite contamination. The densities of the specimens were determined using Archimedes principle. The relative density (\%) was calculated with reference to the theoretical density of the starting powders constituents using the rule of mixtures. The microstructures of the specimens were examined from the polished surface at cross sections (parallel to the acting force) of the sintered bodies; using field emission scanning electron microscope (FESEM, JSM-7600F, Jeol, Japan) with an EDX detector (Oxford X-Max) with an INCA X-Stream 2 pulse analyzer software, and back scattered electron detectors. The INCA analyzer software was set to $70 \mathrm{~s}$ and $2 \mathrm{~s}$ of acquisition and process time respectively. The polished specimens were chemically etched with a $6 \%$ nitric acid solution for 15 seconds to observe the microstructure and measure the grain size. Focus was given to studying the microstructure at different regions along the cross section. Only the cross section of the specimen was examined to avoid the nearsurface effects and some other uncertain factors. The phases present in the sintered specimen were characterized by X-ray diffraction (XRD) using a PANalytical Empyrean model with $\mathrm{Cu} \mathrm{Ka}$ radiation and Highscore plus software. The XRD analysis was carried out on the section perpendicular to uniaxial pressed direction.

\subsection{Mechanical property measurement}

The Vickers micro hardness $\left(\mathrm{HV}_{1}\right)$ at room temperature was measured by a Vickers' micro hardness tester (Future-tech) at a load of $1.0 \mathrm{~kg}$ and dwell time of $10 \mathrm{~s}$. The test result for each sample was the arithmetic mean of ten successive indentations with standard deviations. A Tinius Olsen system (London) measured the bending strength of the sintered alloys, of specimens of 16.00 $\times 5.00 \times 2.00 \mathrm{~mm}^{3}$ with a loading rate of $0.05 \mathrm{~mm} / \mathrm{min}$. The bending strength $\sigma_{b b}$ is calculated from (1):

$\sigma_{\mathrm{bb}}=3 \mathrm{FL} / 2 \mathrm{bh}^{2}$

Where $\sigma_{b b}$ is the bending strength, $\mathrm{F}$ is applied force, $\mathrm{L}$ is length, $\mathrm{b}$ is breadth and $\mathrm{h}$ is the thickness of the sample respectfully.

\section{Results and Discussions}

The mixed powders are of round, non-porous and spherical shapes as illustrated in Figure 1(a). The SEM micrographs of the Ni$30 \% \mathrm{Fe}$ alloy shows the microstructural evolution of the samples with different starting particle size: (a) $3 \mu \mathrm{m} \mathrm{FeNi}$ and (b) $70 \mu \mathrm{m}$ $\mathrm{FeNi}$, where 1 and 2 respectively represent $50^{\circ} \mathrm{C} / \mathrm{min}$ and 150 ${ }^{\circ} \mathrm{C} / \mathrm{min}$ heating rates are presented in Fig. 2. In all cases the sintered specimens produced (a.1, b.1, a.2 \& b.2) in Fig 2 are porous, with fractures (cracks) both on the surface (matrix) as well as at the grain boundaries.
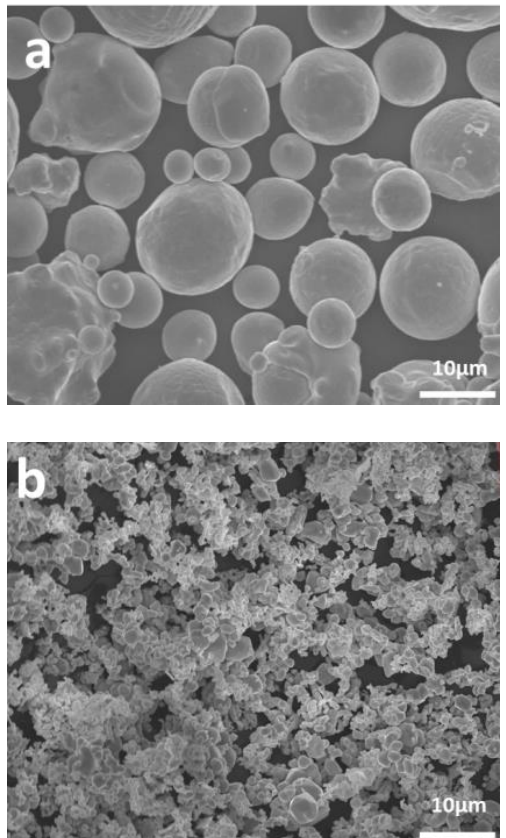

Fig. 1: The Mixed Powder Grains of (A) Ni (70, $0.3 \mu \mathrm{m})$ and (B) $\mathrm{Fe}(44,3$ $\mu \mathrm{m})$. 

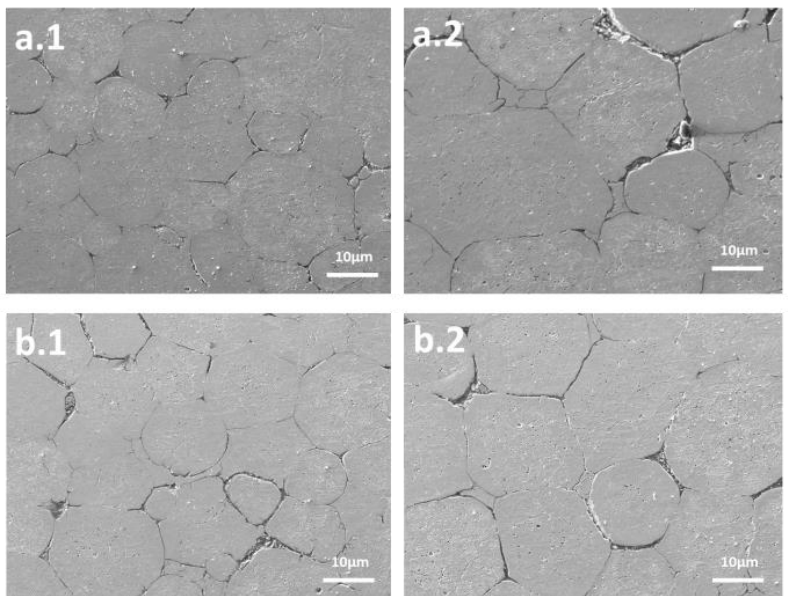

Fig. 2: SEM Micrographs of the Ni-30 \% Fe Alloy Showing the Microstructural Evolution of the Samples with Different Starting Particle Size (A) 3-Feni and (B) 70-Feni, (Where $1=50^{\circ} \mathrm{C} / \mathrm{Min}$ And $2=150{ }^{\circ} \mathrm{C} / \mathrm{Min}$ ).
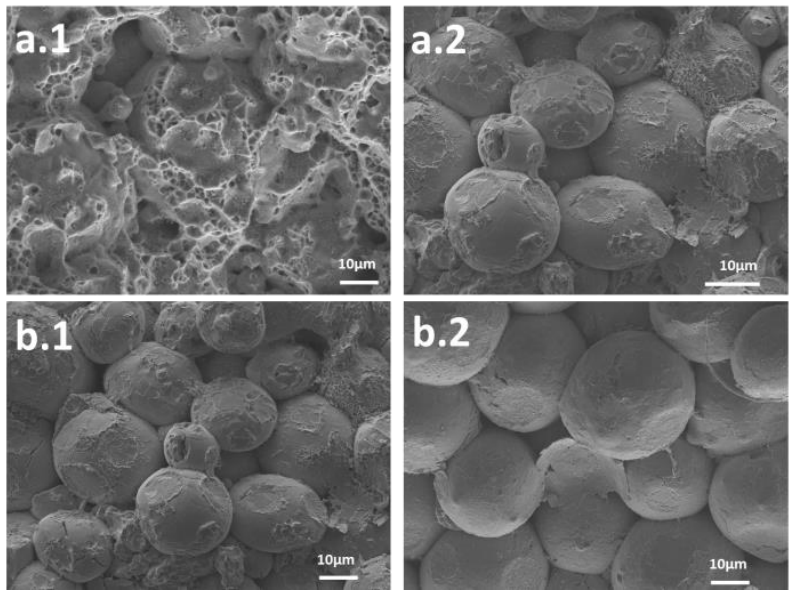

Fig. 3: SEM Micrographs of the Ni-30 \% Fe Alloy Showing the Fracture Surface of the Samples with Different Starting Particle Size: (A) 3-Feni and (B) 70 -Feni, (Where 1 is $50^{\circ} \mathrm{C} / \mathrm{Min}$ and 2 is $150{ }^{\circ} \mathrm{C} / \mathrm{Min}$ ).

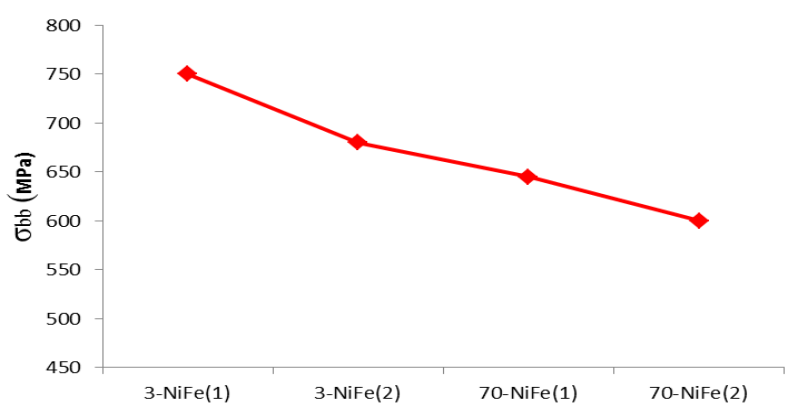

Fig. 4: Effect of Particle Size on Bending Strength, $\left(1\right.$ is $50^{\circ} \mathrm{C} / \mathrm{Min}, 2$ is $\left.150{ }^{\circ} \mathrm{C} / \mathrm{Min}\right)$.

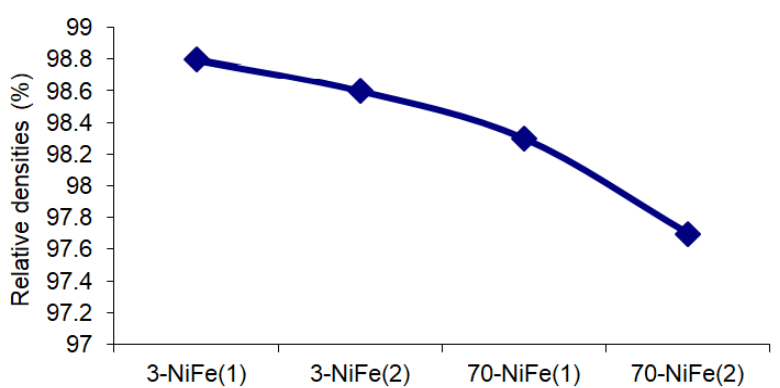

Fig. 5: Effect of Particle Size on Densities, ( 1 is $50^{\circ} \mathrm{C} / \mathrm{Min}, 2$ is 150 $\left.{ }^{\circ} \mathrm{C} / \mathrm{Min}\right)$.

The sintering was done under controlled heating schedules in the vacuum at constant pressure $(30 \mathrm{MPa})$, temperature $\left(1100{ }^{\circ} \mathrm{C}\right)$ and 2 mins heating time. Fig. 2 presents the SEM images of specimens deformed within the heating regime. Comparable microstructures were seen in all specimens that show signs of serrated flow [1011].

Fig. 3 shows the SEM micrographs of the SPS sintered Ni-30\% Fe alloy. It shows the fractured surface of the samples with different (a) $3 \mu \mathrm{m}-\mathrm{FeNi}$ and (b) $70 \mu \mathrm{m}-\mathrm{FeNi}$ starting particle sizes; operated at $50^{\circ} \mathrm{C} / \mathrm{min}$ and $150{ }^{\circ} \mathrm{C} / \mathrm{min}$ heating rates. Fig 3a.1 shows that SPS produced high level of fusion of the particle with sponge like nature of the sinter at the working heating rate. Fig $3 a .2$ shows crack characterized surfaces on the particles. There was high degree / tendency of the diffusion of the smaller or fine particles melting out on the surfaces and at boundaries thereby initiating bonding of the coarse particles. Comparatively, slow heating rates (a.1 and b.1) produced enhanced microstructures hence higher bonding, bending strength and densities than a. 2 and b.2 as obtained in Figs 4 and 5.

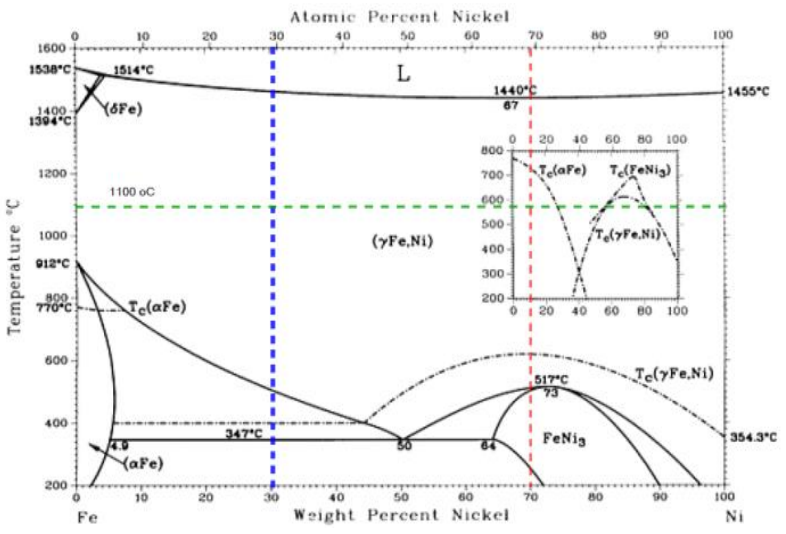

Fig. 6: Fe-Ni (Iron - Nickel) Phase Diagram (ASM 2000).

The effect of particle sizes of $\mathrm{Ni}(70,0.3 \mu \mathrm{m})$ and $\mathrm{Fe}(44,3 \mu \mathrm{m})$; and the heating rates $\left(50^{\circ} \mathrm{C} / \mathrm{min}\right.$ and $\left.150{ }^{\circ} \mathrm{C} / \mathrm{min}\right)$ on bending strengths of $\mathrm{Ni}-30 \% \mathrm{Fe}$ sinters reduced with the heating rates from 50 to $150{ }^{\circ} \mathrm{C} / \mathrm{min}$.

The $3 \mu \mathrm{m} \mathrm{NiFe} \mathrm{(1)} \mathrm{alloy} \mathrm{has} \mathrm{highest} \mathrm{bending} \mathrm{strength} \mathrm{of} \mathrm{about}$ $750 \mathrm{MPa}$ and densification of $98.8 \%$. The results in Figure 4 and 5 matched with the observation in Figure 3.

The sinters produced could be classified as $\gamma$-strengthened (Nirich) $\mathrm{Ni}$-Fe based family. With high $\mathrm{Ni}$ content $(>40 \% \mathrm{Ni})$ in the alloy i.e $\gamma$-strengthened, higher volume fraction $\left(\mathrm{V}_{\mathrm{f}}\right)$ of $\gamma$ results in better high temperature properties; and such $\mathrm{NiFe}$ alloy may be used in structural applications. It is obvious that these alloys are very susceptible to processing and heating regimes. As obtained in the present work (Fig. 1-5), the real phases that are noticed in the finished products are appreciably influenced by heating rate and variations in particle sizes of the mixed $\mathrm{NiFe}$ metal powder.

\section{Conclusion}

The effects of grain distribution and heating rate on bending strength of mixed coarse-fine sized sintered Ni-30\%Fe Alloys have been studied and from the results obtained, the following conclusions are made: The morphology and the microstructures of the powders and sinters showed that the mixed powders are of round, non-porous and spherical shapes.

The microstructural evolution of the samples with different starting particle size: (a) $3 \mu \mathrm{m}-\mathrm{FeNi}$ and (b) $70 \mu \mathrm{m}-\mathrm{FeNi}$, sintered at $50{ }^{\circ} \mathrm{C} / \mathrm{min}$ and $150{ }^{\circ} \mathrm{C} / \mathrm{min}$ heating rates revealed that in all cases, the sintered specimens produced (a.1, b.1, a.2 \& b.2) are porous, with fractures (cracks) both on the surface (matrix) as well as at the grain boundaries.

The SEM imagery showed that specimens deformed within the heating regime. Comparable microstructures were seen in all specimens that show signs of serrated flow. It also shows that SPS produced high level of fusion of the particle with sponge like nature of the sinter at the working heating rate. Comparatively, slow 
heating rates (a.1 \& b.1) produced enhanced microstructures hence higher bonding, bending strength and densities than a. $2 \&$ b. 2

\section{Acknowledgement}

This work is based on the research supported in part by the National Research Foundation of South Africa for the grant, Unique Grant No. 99348. Research facilities support by the Institute for NanoEngineering Research, Tshwane University of Technology, Pretoria, South Africa.

Ajibola O.O thanks the University of Oye Ekiti, Oye-Ekiti, Nigeria, for the postdoctoral fellowship leave.

\section{Conflict of interests}

The authors declare that there is no conflict of interests as regarding the publication of this paper.

\section{References}

[1] H. Czichos, D. Klaffke, E. Santner and M. Woydt. "Advances in tribology: the materials point of view", Wear, Vol. 190, No 2 (1995), pp 155-161. doi.org/10.1016/0043-1648 (96)80014-7.

[2] ASM Specialty Handbook: Nickel, Cobalt, and their Alloys (\#06178G), ASM International, 2000.

[3] J.C. Hey, and A.P. Jardine, "Shape memory TiNi synthesis from elemental powders" Material Science and Engineering A., Vol 188, No 1-2, (1994), pp291-300. https://doi.org/10.1016/09215093(94)90384-0

[4] B.Y. Li, L.J. Rong, \& Y.Y. Li, "Porous NiTi alloy prepared from elemental powder sintering", Journal Materials Research. Vol. 13, No 10, (1998), pp2847-2851.

https://doi.org/10.1557/JMR.1998.0389.

[5] A. Bansiddhi and D.C. Dunand, "Shape-memory NiTi-Nb foams", Journal Materials Research. Vol. 24, No 6, (2009), pp 2107-2117. https://doi.org/10.1557/jmr.2009.0256.

[6] T. Majewski, "Investigations of Production Processes of W-Re-Ni and W-Re-Ni-Fe Heavy Metals", Solid State Phenomena, Vol. 165 (2010), pp. 124-129. https://doi.org/10.4028/www.scientific.net/SSP.165.124.

[7] M.L. Marucci, G. Fillari, P. King, and K. S. Narasimhan, "A review of current. sinter-hardening technology" PM 2004 World Congress, Vienna, Austria.

[8] J. Räthel, M. Herrmann and W. Beckert. "Temperature distribution for electrically conductive and non-conductive materials during Field Assisted Sintering (FAST)". Journal European Ceramic Society. Vol 29, No 8, (2009), pp 1419-1425. https://doi.org/10.1016/j.jeurceramsoc.2008.09.015.

[9] A. Zavaliangos, J. Zhang, M. Krammer, and JR. Groza. "Temperature evolution during field activated sintering "Material Science Engineering A, Vol. 379, No 1-2, (2004), pp.218-228. https://doi.org/10.1016/j.msea.2004.01.052.

[10] M.B.Shongwe, M.M.Ramakokovhu, S.Diouf, M.O.Durowoju, B.A Obadele, R. Sule, M. L. Lethabane, P. A. Olubambi, "Effect of starting powder particle size and heating rate on spark plasma sintering of FeNi alloys", Journal of Alloys and Compounds, Vol. 678, (2016), pp 241-248. https://doi.org/10.1016/j.jallcom.2016.03.270.

[11] M.B. Shongwe, I. M. Makena, M.M. Ramakokovhu, T. Langa, P.A Olubambi. "Sintering behavior and effect of ternary additions on the microstructure and mechanical properties of $\mathrm{Ni}-\mathrm{Fe}$-based alloy". Particulate Science and Technology. Vol 35, April 2017 https://doi.org/10.1080/02726351.2017.1298686.

[12] M.B. Shongwe, I. M. Makena, O.O. Ajibola, P.A. Olubambi, F.V. Adams. "Investigation of ternary additions on corrosion resistance of spark plasma sintered 50Ni40Fe alloys in $\mathrm{H}_{2} \mathrm{SO}_{4}$ and $\mathrm{NaCl}$ ". Bulletin of the Chemical Society of Ethiopia. Vol. 32, No. 2, pp 337 349. 